\title{
Skeletonization of bilateral internal thoracic artery grafts lowers the risk of sternal infection in patients with diabetes
}

Mark D. Peterson, MD

Michael A. Borger, MD, PhD

Vivek Rao, MD, PhD

Charles M. Peniston, MD

Christopher M. Feindel, MD

From the Division of Cardiac Surgery, Toronto General Hospital, Department of Surgery, University of Toronto, Toronto, Ontario, Canada.

Received for publication Jan 13, 2003; revisions requested March 6, 2003; revisions received April 7, 2003; accepted for publication May 16, 2003.

Address for reprints: Michael A. Borger, $\mathrm{MD}, \mathrm{PhD}$, Division of Cardiac Surgery, Toronto General Hospital EN 13-217, 200 Elizabeth Street, Toronto, Ontario, Canada, M5G 2C4 (E-mail: michael.borger@uhn. on.ca).

J Thorac Cardiovasc Surg 2003;126:1314-9

Copyright (C) 2003 by The American Association for Thoracic Surgery

$0022-5223 / 2003 \$ 30.00+0$

doi:10.1016/S0022-5223(03)00808-0
Objective: Deep sternal wound infection is a dreaded complication of coronary artery bypass surgery, particularly in patients with diabetes. This study determines whether skeletonization of internal thoracic artery conduits compared with pedicled harvesting reduces the risk of deep sternal wound infection in patients with diabetes undergoing bilateral internal thoracic artery grafting.

Methods: We reviewed prospectively gathered data on all patients who have undergone coronary artery bypass grafting and received bilateral internal thoracic artery grafts at our institution since 1990 . We compared patients with diabetes who received skeletonized $(n=79)$ versus conventional pedicled $(n=36)$ internal thoracic artery conduits.

Results: The proportion of patients taking insulin (19.0\% vs $14.0 \%$ for skeletonized vs conventional grafts, respectively, $P=.6)$ or oral hypoglycemic agents $(68.4 \%$ vs $69.4 \%, P=.9)$, as well as the prevalence of type I diabetes $(2.5 \%$ vs $8.3 \%, P=.18)$, were similar in both groups. Patients who received skeletonized grafts were more likely to receive a free rather than an in situ right internal thoracic artery graft (93.7\% vs $30.6 \%, P<.001)$. The prevalence of deep sternal wound infection was significantly lower in patients who received skeletonized grafts compared with patients who received conventional grafts $(1.3 \%$ vs $11.1 \%, P=.03)$. Patients in the skeletonized group were also less likely to develop any (superficial or deep) sternal wound infection postoperatively $(5.1 \%$ vs $22.2 \%, P=.03)$. There was no significant difference in the prevalence of deep sternal wound infection between patients with diabetes who received skeletonized internal thoracic arteries and patients without diabetes who underwent conventional internal thoracic artery grafting $(\mathrm{n}=578)$ $(1.2 \%$ vs $1.6 \%$, respectively, $P=.8)$.

Conclusions: Skeletonization of internal thoracic artery conduits lowers the risk of deep sternal wound infection in patients with diabetes undergoing bilateral internal thoracic artery grafting. We no longer consider diabetes a contraindication to bilateral internal thoracic artery grafting, provided the internal thoracic arteries are skeletonized.

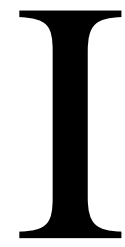
$t$ has been clearly demonstrated that the use of 1 internal thoracic artery (ITA) graft during coronary artery bypass grafting (CABG) results in excellent long-term graft patency, reduced risk of recurrent angina, and improved survival. ${ }^{1}$ Recent evidence indicates that bilateral ITA grafting further improves survival and reduces the need for repeat revascularization. ${ }^{2,3}$ ITA grafting is particularly important for patients with diabetes, because survival is significantly higher in patients with diabetes after CABG 
compared with percutaneous transluminal angioplasty. ${ }^{4}$ Furthermore, the higher survival in the patients with diabetes after CABG was limited to patients who received ITA grafts.

Patients with diabetes represent a subgroup of patients who could potentially derive the greatest benefit from bilateral ITA grafting. Unfortunately, this technique is limited by the increased risk of deep sternal wound infection associated with conventional pedicled ITA harvesting. ${ }^{5}$ Indeed, diabetes is a well-recognized risk factor for sternal infection even in patients receiving a single ITA graft. ${ }^{5,6}$ Pedicled harvesting of both ITA grafts may impair sternal wound healing by decreasing sternal blood flow, resulting in an increased risk of sternal wound infection and dehiscence. ${ }^{7,8}$

Recently, skeletonization of ITA grafts has been suggested as a technique that results in less devascularization of the sternum. ${ }^{8}$ Skeletonization involves meticulous dissection of the ITA conduit away from the chest wall, with preservation of the collateral sternal blood supply and the internal thoracic veins. This study determines whether skeletonization of ITA conduits reduces the risk of deep sternal wound infection in patients with diabetes undergoing bilateral ITA grafting.

\section{Methods}

We reviewed prospectively collected data on all patients who have received bilateral ITA grafts at our institution since 1990. Institutional ethics approval was obtained before the study. Since 1999, skeletonization of ITA grafts has been performed routinely by 2 of our surgeons (C.M.P. and C.M.F.) on all patients undergoing CABG. Most skeletonized ITA grafts were harvested by the 2 staff surgeons early in the study, with progressively more harvests being performed by cardiac surgery residents and fellows over time. Pedicled ITA grafts were harvested by a combination of attending surgeons, fellows, and residents.

We compared patients with diabetes who received skeletonized $(\mathrm{n}=79)$ versus conventional pedicled $(\mathrm{n}=36)$ bilateral ITA grafts. Patients without diabetes who underwent conventional bilateral ITA grafting $(n=578)$ were also compared with patients with diabetes who received skeletonized bilateral ITA conduits. We excluded patients who underwent concomitant cardiac or extracardiac procedures.

\section{Perioperative Management}

Bilateral ITA grafting with skeletonized or pedicled grafts was performed in all patients. Saphenous vein segments and radial arteries were used as additional bypass conduits as required to perform complete myocardial revascularization. Cardiopulmonary bypass and blood cardioplegia were used in all patients.

On the morning of the operation, the hair overlying potential surgical sites was removed on all patients with hair clippers, followed by an antiseptic wash with a $2 \%$ chlorhexidine gluconate solution (Endure 420; Ecolab, St Paul, Minn). In addition, a complete surgical scrub of the chest and potential donor graft sites was performed with a $7.5 \%$ povidone-iodine soap solution in the operating room, followed by a $10 \%$ povidone-iodine clear solu- tion. An iodoform-impregnated adhesive plastic sheet (Ioban; 3M, Brookings, SD) was routinely applied to the chest. Intravenous cefazolin (1 g) or clindamycin $(600 \mathrm{mg})$ was administered before skin incision. The skin was incised with a scalpel, and electrocautery was used to open the presternal layers and pericardium. A median sternotomy was performed in all patients. Bone wax was used sparingly, and excessive use of electrocautery on the sternum was avoided.

The pleural space was partially opened in most patients undergoing skeletonized ITA harvesting and widely opened in patients undergoing pedicled ITA harvesting. Skeletonized ITA grafts were dissected as isolated arteries, leaving the adjacent veins and muscle undisturbed. Arterial branches were divided with microscissors between proximal and distal hemoclips. The left skeletonized ITA grafts were mobilized from the first rib to the bifurcation of the ITA into the superior epigastric and musculophrenic arteries. The right ITA grafts were mobilized from the bifurcation to the sternomanubrial junction if used as a free graft or to the first rib if used as an in situ graft. The proximal extent of dissection for free grafts was 1 rib space less than for in situ harvesting. Pedicled ITAs were harvested with the standard technique; that is, pedicled ITAs were dissected from the thoracic wall, along with the accompanying internal thoracic veins, muscle, and fascia, using electrocautery. Arterial side branches were controlled proximally with small hemoclips and distally with electrocautery. Both ITAs were divided after systemic heparinization and immersed in a solution of papaverine $(2 \mathrm{cc})$ and blood $(8 \mathrm{cc})$.

Before initiation of cardiopulmonary bypass, free right ITAs were anastomosed as a $\mathrm{T}$ graft to in situ left ITAs with a continuous 7-0 polypropylene suture. Saphenous vein and radial arterial grafts were constructed before distal ITA grafting. Before chest closure, the pericardium and thymic tissue were approximated to protect the ITAs from injury in case of repeat sternotomy. Sump drains were placed in the mediastinum, and chest tubes were inserted into the pleural spaces, if opened. The sternum was closed with stainless steel wires. The presternal space was closed with 2 layers of absorbable suture, and the skin was closed with a subcuticular absorbable suture. Patients were extubated when they were hemodynamically stable, normothermic, and ventilating spontaneously.

Deep sternal wound infection was defined according to the guidelines of the Centers for Disease Control and Prevention, with patients meeting at least 1 of the following criteria: (1) isolation of an organism from culture of mediastinal tissue or fluid; (2) evidence of mediastinitis during sternal reexploration; or (3) chest pain, sternal instability, or fever present in combination with purulent discharge from the mediastinum or an isolated organism from blood or tissue cultures. ${ }^{10}$ Superficial sternal infection was defined as wound erythema and purulent discharge without evidence of sternal or mediastinal involvement.

\section{Statistical Analysis}

Statistical analysis was performed with SAS software (version 8.1; SAS Institute, Cary, NC). Continuous variables are expressed as mean $\pm \mathrm{SD}$, and categoric variables are expressed as percentages throughout the article. Comparisons of continuous variables between groups were performed with unpaired Student $t$ tests or the Kruskal-Wallis test. Categoric variables were analyzed with $\chi^{2}$ or 
TABLE 1. Preoperative characteristics of patients with diabetes who received skeletonized or conventional bilateral ITA conduits

\begin{tabular}{lccc}
\hline Variable & $\begin{array}{c}\text { Skeletonized } \\
(\mathbf{n}=\mathbf{7 9})\end{array}$ & $\begin{array}{c}\text { Conventional } \\
(\mathbf{n}=\mathbf{3 6})\end{array}$ & $\boldsymbol{P}$ value \\
\hline Age & $60.1 \pm 9.3$ & $56.6 \pm 11.6$ & .09 \\
Male sex & $74(93.7 \%)$ & $28(77.8 \%)$ & .02 \\
Urgent timing & $4(5.1 \%)$ & $2(5.6 \%)$ & .2 \\
Hypertension & $53(67.1 \%)$ & $17(47.2 \%)$ & .06 \\
Class CCS $\geq 3$ & $33(41.8 \%)$ & $22(61.1 \%)$ & .3 \\
Class NYHA $\geq 3$ & $28(77.8 \%)$ & $54(68.4 \%)$ & .4 \\
Preoperative MI & $9(11.4 \%)$ & $9(25.7 \%)$ & .13 \\
LVEF $\leq 40 \%$ & $12(15.2 \%)$ & $7(19.4 \%)$ & .8 \\
PVD & $11(13.9 \%)$ & $6(16.7 \%)$ & .8 \\
Renal failure & 0 & $2(5.6 \%)$ & .1 \\
COPD & $2(2.5 \%)$ & $6(16.7 \%)$ & .01 \\
Smoking history & $54(68.4 \%)$ & $26(72.2 \%)$ & .9 \\
Body mass index & $27.9 \pm 5.1$ & $28.3 \pm 4.5$ & .7 \\
Type II DM & $77(97.5 \%)$ & $33(91.7 \%)$ & .18 \\
Taking insulin & $15(19.0 \%)$ & $5(14.0 \%)$ & .6 \\
Taking OHGs & $54(68.4 \%)$ & $25(69.4 \%)$ & .9 \\
\hline
\end{tabular}

CCS, Canadian Cardiovascular Society; NYHA, New York Heart Association; $M I$, myocardial infarction; $L V E F$, left ventricular ejection fraction; $P V D$, peripheral vascular disease; $C O P D$, chronic obstructive pulmonary disease; DM, diabetes mellitus; $O H G$ s, oral hypoglycemic agents; ITA, internal thoracic artery.

TABLE 2. Intraoperative characteristics of patients with diabetes who received skeletonized or conventional bilateral ITA conduits

\begin{tabular}{lccc}
\hline Variable & $\begin{array}{c}\text { Skeletonized } \\
(\mathbf{n}=\mathbf{7 9})\end{array}$ & $\begin{array}{c}\text { Conventional } \\
(\mathbf{n}=\mathbf{3 6})\end{array}$ & $\boldsymbol{P}$ value \\
\hline Total operative time (min) & $199.3 \pm 75.1$ & $184.7 \pm 69.7$ & .3 \\
Crossclamp time (min) & $65.8 \pm 21.6$ & $60.4 \pm 26.6$ & .3 \\
CPB time (min) & $83.7 \pm 25.0$ & $87.2 \pm 35.7$ & .6 \\
No. of bypass grafts & $3.9 \pm 0.9$ & $3.9 \pm 1.1$ & .4 \\
Free RITA graft & $74(93.7 \%)$ & $11(30.6 \%)$ & $<.001$
\end{tabular}

$C P B$, Cardiopulmonary bypass; RITA, right internal thoracic artery.

Fisher's exact tests. Backward stepwise logistic regression identified independent predictors of deep sternal wound infection.

\section{Results}

Patients in the 2 groups were similar for all preoperative variables, with the exception of a greater proportion of men and a lower prevalence of chronic obstructive pulmonary disease in the skeletonized group (Table 1). The prevalence of type I diabetes mellitus, the use of oral hypoglycemic agents, and the proportion of patients using insulin were similar between the 2 groups.

The intraoperative variables were also similar between the 2 groups of patients (Table 2). However, the proportion of patients receiving free right ITA grafts was significantly greater in the skeletonized group compared with the con-
TABLE 3. Postoperative outcomes of patients with diabetes who received skeletonized or conventional bilateral ITA conduits

\begin{tabular}{lccl}
\hline Outcome & $\begin{array}{c}\text { Skeletonized } \\
(\mathbf{n}=\mathbf{7 9})\end{array}$ & $\begin{array}{c}\text { Conventional } \\
(\mathbf{n}=\mathbf{3 6})\end{array}$ & $\boldsymbol{P}$ value \\
\hline Perioperative MI & 0 & $1(2.8 \%)$ & .3 \\
Low output syndrome & 0 & $5(13.9 \%)$ & .003 \\
IABP & 0 & $4(11.1 \%)$ & .01 \\
Renal failure & 0 & $1(2.8 \%)$ & .3 \\
Stroke & $1(1.3 \%)$ & 0 & .5 \\
RBC transfusions & $0.7 \pm 1.0$ & $2.5 \pm 4.3$ & .016 \\
Resternotomy for bleeding & $4(5.1 \%)$ & $1(2.8 \%)$ & .6 \\
Ventilation (h) & $9.1 \pm 15.4$ & $22.9 \pm 35.7$ & .03 \\
ICU stay (d) & $1.5 \pm 1.3$ & $2.4 \pm 2.2$ & .03 \\
Hospital stay (d) & $7.1 \pm 2.9$ & $11.2 \pm 9.2$ & .013 \\
Mortality & 0 & $2(5.6 \%)$ & .10 \\
\hline
\end{tabular}

$I A B P$, Intra-aortic balloon pump; $R B C$, red blood cell; $I C U$, intensive care unit.

ventional group. Skeletonization of ITA grafts did not significantly increase operative times.

Patients receiving pedicled bilateral ITA grafts demonstrated a significantly higher incidence of low output syndrome and intra-aortic balloon pump insertion (Table 3). The duration of postoperative ventilatory support, intensive care unit stay, and hospital stay were also significantly increased in the conventional ITA group.

Figure 1 reveals that patients with diabetes who underwent a skeletonized bilateral ITA demonstrated a significantly lower incidence of postoperative sternal wound infections (superficial or deep) than patients who underwent a conventional bilateral ITA ( $5.1 \%$ vs $22.2 \%$, respectively, $P$ $=.03$ ). In addition, the incidence of deep sternal wound infection was significantly lower in the skeletonized than the conventional group $(1.3 \%$ vs $11.1 \%, P=.03)$ (Figure 2).

We performed a stepwise logistic regression to identify independent predictors of sternal wound infection in all patients with diabetes who received bilateral ITA grafts. Pedicled harvesting of ITA conduits (odds ratio 8.2; 95\% confidence interval 1.9-36.4) and peripheral vascular disease (odds ratio 7.6; 95\% confidence interval 1.7-33.2) were the only independent predictors of sternal wound infection.

We also compared the incidence of sternal wound infection between patients with diabetes who received skeletonized bilateral ITA grafts with patients without diabetes who received conventional bilateral ITA grafts $(n=578)$. The overall incidence of sternal wound infection (superficial or deep) was similar between these 2 groups of patients (4.8\% and $4.2 \%$, respectively, $P=.8$ ). Similarly, the incidence of deep sternal wound infection was not significantly higher for the patients with diabetes compared with the patients without diabetes $(1.2 \%$ vs $1.6 \%$, respectively, $P=.8)$ (Figure 3). 


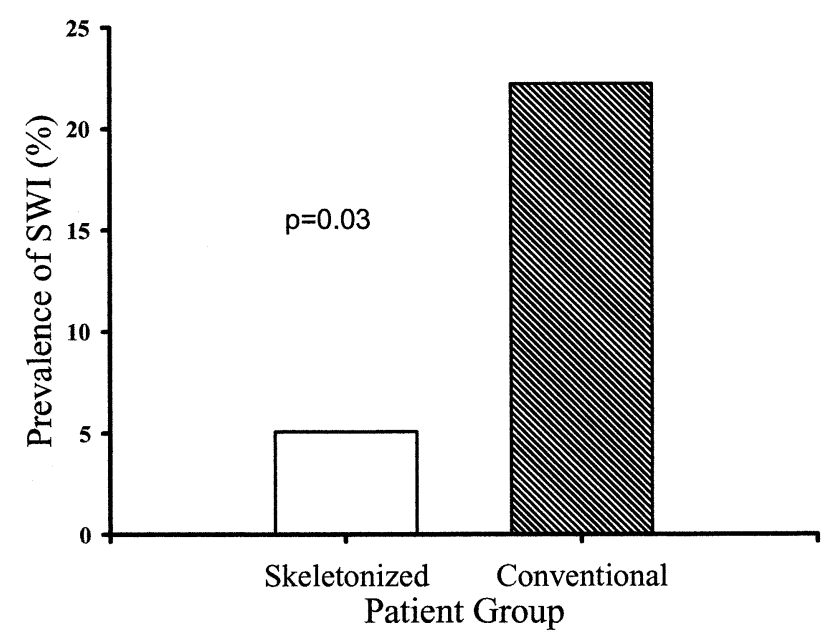

Figure 1. Prevalence of any (superficial or deep) sternal wound infection (SWI) in patients receiving bilateral ITAs; skeletonized versus conventional.

\section{Discussion}

Arterial grafting during coronary bypass surgery is routinely performed as a result of the success of left ITA grafting of the left anterior descending artery. ${ }^{1}$ Compared with saphenous vein bypass grafting, patients who receive an ITA to the left anterior descending artery survive longer and experience less hospitalization for cardiac events, lower rates of cardiac reoperation, and less frequent myocardial infarction. It has been suggested that further benefits can be achieved by using more than 1 ITA graft. Indeed, 2 recent metaanalyses that compared outcomes after single versus bilateral ITA grafting demonstrate that the latter results in higher long-term survival. ${ }^{11,12}$ None of the studies included in these meta-analyses were randomized; therefore, patient selection bias may have accounted for some of the observed benefit. In particular, the proportion of patients with diabetes, low ejection fraction, and increased age varied between the single and bilateral ITA study populations. Lytle and colleagues $^{2}$ attempted to address possible selection bias by using propensity score matching of patients undergoing single and bilateral ITA grafting. These investigators concluded that the use of bilateral ITA conduits significantly and independently decreases the risk of long-term death, reoperation, and angioplasty.

Despite accumulating evidence of prolonged survival and decreased cardiac events, many surgeons avoid bilateral ITA grafting because of the increased risk of sternal infection, especially in patients with diabetes. ${ }^{5,6}$ Deep sternal wound infection is a dreaded complication that portends an increased risk of morbidity and death. ${ }^{13} \mathrm{We}$ previously demonstrated that patients who develop deep sternal infection have a 3-fold increase in intensive care unit and hos-

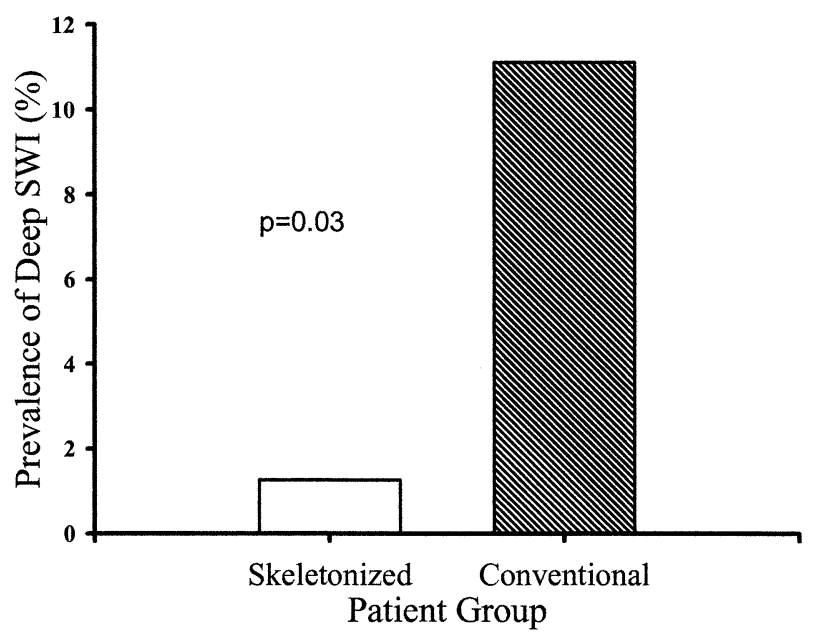

Figure 2. Prevalence of deep SWI in patients receiving bilateral ITAs: skeletonized versus conventional.

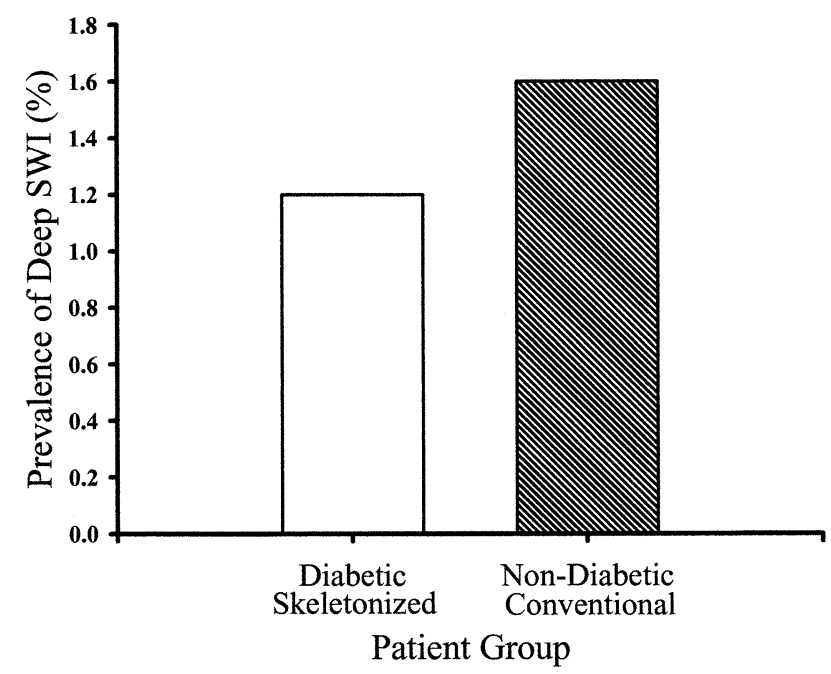

Figure 3. Prevalence of deep SWI in patients with and without diabetes receiving ITAs: skeletonized versus conventional, respectively.

pital length of stay, as well as a 3-fold increase in mortality. ${ }^{6}$

The increased risk of sternal infection after bilateral ITA grafting is most likely caused by sternal ischemia. Several clinical and laboratory studies have demonstrated reduced ipsilateral sternal blood flow after pedicled ITA harvesting. ${ }^{7,14,15}$ Skeletonization of ITA conduits, however, results in less reduction of sternal blood flow. ${ }^{8,9}$ Anatomic studies reveal that the sternal and anterior intercostal branches of the ITA originate either directly or as a common trunk from the ITA. ${ }^{16}$ Substantial collateral blood flow to the sternum can be maintained in the absence of the ITA, provided the 
sternal-anterior intercostal trunk is left intact. Skeletonization of the ITA often results in preservation of this common trunk, particularly if meticulous dissection is performed. We therefore hypothesized that skeletonization would lower the risk of sternal infection, particularly in high-risk patients.

The current study confirms an unacceptably high prevalence of deep sternal wound infection in patients with diabetes receiving pedicled bilateral ITA grafts $(11.1 \%$, Figure 2). Skeletonization of both conduits resulted in a significantly lower prevalence of deep sternal infection $(1.2 \%)$ that was comparable to rates in patients without diabetes $(1.6 \%$, Figure 3 ). The prevalence of any sternal infection (superficial or deep) was also significantly lower in patients in the skeletonized group. We conclude that skeletonization allows safe application of bilateral ITA grafting in patients with diabetes, a finding that has been demonstrated by others. ${ }^{17}$

Although skeletonization is associated with a decreased risk of wound infection, some potential drawbacks should be addressed. First, skeletonization may be more technically difficult than pedicled ITA harvesting and may increase the risk of conduit injury. In the current study, we found an insignificant 15-minute increase in operating times for patients undergoing skeletonization. However, we believe that skeletonization can be safely performed, and that the risk of ITA injury is small. Experimental studies reveal that skeletonization does not result in more histologic or endothelial damage than pedicled ITA harvesting. ${ }^{18,19}$ Furthermore, skeletonized ITA conduits have better intraoperative blood flow than pedicled conduits, as well as increased length. ${ }^{19,20}$ The latter finding may be important for patients with distal coronary targets.

Another potential drawback of skeletonization is that it is a relatively new surgical technique, and therefore current data are lacking on long-term patency rates. Early and midterm patency studies have yielded very encouraging results. ${ }^{21,22}$ Although further studies are required, it is unlikely that long-term patency rates will be worse than for pedicled ITA grafts.

A potential benefit of skeletonization, in addition to the decreased risk of sternal infection, is decreased postoperative chest wall pain. Intercostal nerve damage occurs frequently after pedicled ITA harvesting. ${ }^{23}$ We previously demonstrated that three quarters of patients who underwent coronary bypass showed evidence of intercostal nerve damage after pedicled harvesting, and that $15 \%$ of these patients experienced persistent postoperative pain. ${ }^{24}$ The anterior branch of the intercostal nerve is avoided during skeletonized harvesting, which may in turn decrease the frequency and severity of postoperative chronic chest wall pain.

It should be noted that patients who received skeletonized grafts fared better than patients who received pedicled grafts for outcomes other than sternal infection (Table 3).
Skeletonization was associated with a lower prevalence of low cardiac output syndrome and intra-aortic balloon use. Improvement in early cardiac outcomes may relate to the increased conduit diameter and blood flow reported in skeletonized compared with pedicled grafts. ${ }^{19,20}$ Our study also revealed that patients who received skeletonized grafts had lower red blood cell transfusion requirements (Table 3), a finding that may be explained by the meticulous dissection and hemostasis that is necessary during skeletonization.

Finally, our study revealed that patients who received skeletonized grafts had shorter ventilation times, intensive care unit stays, and hospital stays than patients who received pedicled grafts (Table 3). We do not believe that these improvements were caused by ITA skeletonization per se, rather they were caused by differences in the date of the procedures. In the current study, patients who received a pedicled graft underwent operation between 1990 and 2002, whereas skeletonization was not performed until 1999. We adopted early extubation and "fast-tracking" protocols at our institution in the mid-1990s, which was likely responsible for the decreased ventilation times and lengths of stay for patients in the skeletonized group. Indeed, this potential time bias is the main limitation of our study. It should be stressed, however, that we did not change any of our practices related to sternal infection during the entire 12-year study period. Therefore, we feel justified in concluding that skeletonization lowers the risk of sternal infection in highrisk patients.

\section{Conclusion}

ITA skeletonization lowers the risk of sternal infection in patients with diabetes, resulting in infection rates that are similar to those in patients without diabetes. We no longer consider diabetes a contraindication to bilateral ITA grafting, provided skeletonization is performed. Although longterm patency results are pending, we believe that skeletonization is a safe and effective method of ITA harvesting.

\section{References}

1. Loop FD, Lytle BW, Cosgrove DM, Stewart RW, Goormastic M, Williams GW, et al. Influence of the internal-mammary-artery graft on 10-year survival and other cardiac events. N Engl J Med. 1986;314: 1-6.

2. Lytle BW, Blackstone EH, Loop FD, Houghtaling PL, Arnold JH, Akhrass R, et al. Two internal thoracic artery grafts are better than one. J Thorac Cardiovasc Surg. 1999;117:855-72.

3. Endo M, Nishida H, Tomizawa Y, Kasanuki H. Benefit of bilateral over single internal mammary artery grafts for multiple coronary artery bypass grafting. Circulation. 2001;104:2164-70.

4. [No authors listed]. Comparison of coronary bypass surgery with angioplasty in patients with multivessel disease. The Bypass Angioplasty Revascularization Investigation (BARI) Investigators. $N$ Engl J Med. 1996;335:217-25.

5. Grossi EA, Esposito R, Harris LJ, Crooke GA, Galloway AC, Colvin $\mathrm{SB}$, et al. Sternal wound infections and use of internal mammary artery grafts. J Thorac Cardiovasc Surg. 1991;102:342-6.

6. Borger MA, Rao V, Weisel RD, Ivanov J, Cohen G, Scully HE, et al. 
Deep sternal wound infection: risk factors and outcomes. Ann Thorac Surg. 1998;65:1050-6.

7. Arnold M. The surgical anatomy of sternal blood supply. J Thorac Cardiovasc Surg. 1972;64:596-610.

8. Lorberboym M, Medalion B, Bder O, Lockman J, Cohen N, Schachner $\mathrm{A}$, et al. $99 \mathrm{mTc}$-MDP bone SPECT for the evaluation of sternal ischaemia following internal mammary artery dissection. Nucl Med Commun. 2002;23:47-52.

9. Cohen AJ, Lockman J, Lorberboym M, Bder O, Cohen N, Medalion B, et al. Assessment of sternal vascularity with single photon emission computed tomography after harvesting of the internal thoracic artery. J Thorac Cardiovasc Surg. 1999;118:496-502.

10. Garner JS, Jarvis WR, Emori TG, Horan TC, Hughes JM. CDC definitions for nosocomial infections, 1988. Am J Infect Control. 1988;16:128-40.

11. Taggart DP, D'Amico R, Altman DG. Effect of arterial revascularisation on survival: a systematic review of studies comparing bilateral and single internal mammary arteries. Lancet. 2001;358:870-5.

12. Rizzoli G, Schiavon L, Bellini P. Does the use of bilateral internal mammary artery (IMA) grafts provide incremental benefit relative to the use of a single IMA graft? A meta-analysis approach. Eur J Cardiothorac Surg. 2002;22:781-6.

13. Loop FD, Lytle BW, Cosgrove DM, Mahfood S, McHenry MC, Goormastic M, et al. J. Maxwell Chamberlain memorial paper. Sternal wound complications after isolated coronary artery bypass grafting: early and late mortality, morbidity, and cost of care. Ann Thorac Surg. 1990;49:179-86.

14. Parish MA, Asai T, Grossi EA, Esposito R, Galloway AC, Colvin SB, et al. The effects of different techniques of internal mammary artery harvesting on sternal blood flow. J Thorac Cardiovasc Surg. 1992; 104:1303-7.
15. Seyfer AE, Shriver CD, Miller TR, Graeber GM. Sternal blood flow after median sternotomy and mobilization of the internal mammary arteries. Surgery. 1988;104:899-904.

16. Henriquez-Pino JA, Gomes WJ, Prates JC, Buffolo E. Surgical anatomy of the internal thoracic artery. Ann Thorac Surg. 1997;64:1041-5.

17. Matsa M, Paz Y, Gurevitch J, Shapira I, Kramer A, Pevny D, et al. Bilateral skeletonized internal thoracic artery grafts in patients with diabetes mellitus. J Thorac Cardiovasc Surg. 2001;121:668-74.

18. Gaudino M, Toesca A, Nori SL, Glieca F, Possati G. Effect of skeletonization of the internal thoracic artery on vessel wall integrity. Ann Thorac Surg. 1999;68:1623-7.

19. Deja MA, Wos S, Golba KS, Zurek P, Domaradzki W, Bachowski R, et al. Intraoperative and laboratory evaluation of skeletonized versus pedicled internal thoracic artery. Ann Thorac Surg. 1999;68:2164-8.

20. Takami Y, Ina H. Effects of skeletonization on intraoperative flow and anastomosis diameter of internal thoracic arteries in coronary artery bypass grafting. Ann Thorac Surg. 2002;73:1441-5.

21. Calafiore AM, Vitolla G, Iaco AL, Fino C, Di Giammarco G, Marchesani F, et al. Bilateral internal mammary artery grafting: midterm results of pedicled versus skeletonized conduits. Ann Thorac Surg. 1999;67:1637-42.

22. Bical O, Braunberger E, Fischer M, Robinault J, Foiret JC, Fromes Y, et al. Bilateral skeletonized mammary artery grafting: experience with 560 consecutive patients. Eur J Cardiothorac Surg. 1996;10:971-5.

23. Mailis A, Chan J, Basinski A, Feindel C, Vanderlinden G, Taylor A, et al. Chest wall pain after aortocoronary bypass surgery using internal mammary artery graft: a new pain syndrome? Heart Lung. 1989;18: 553-8.

24. Mailis A, Umana M, Feindel CM. Anterior intercostal nerve damage after coronary artery bypass graft surgery with use of internal thoracic artery graft. Ann Thorac Surg. 2000;69:1455-8. 